\title{
The formation of dinuclear trichloro-bridged and mononuclear ruthenium complexes from the reactions of dichlorotris( $p$-tolylphosphine)ruthenium(II) with diazabutadiene ligands
}

\author{
Meng Guan Tay ${ }^{1}\left[\right.$. Ying Ying Chia ${ }^{1} \cdot$ Suzie Hui Chin Kuan ${ }^{1} \cdot$ Tze Pei Phan $^{1}$
}

Received: 18 September 2018 / Accepted: 24 November 2018 / Published online: 17 December 2018

(c) Springer Nature Switzerland AG 2018

\begin{abstract}
$\mathrm{Ru}(\mathrm{II})$ complexes with diazabutadiene (R-DAB) ligands have been prepared. The reaction of $\mathrm{RuCl}_{3} \cdot n \mathrm{H}_{2} \mathrm{O}$ with $\mathrm{P}(p \text {-tolyl })_{3}$ gave a $\left[\mathrm{RuCl}_{2}\left\{\mathrm{P}(p \text {-tolyl })_{3}\right\}\right]$ precursor, whose reactions with $\mathrm{R}-\mathrm{DAB}$ in toluene gave dinuclear trichloro-bridged $\mathrm{Ru}(\mathrm{II})$ complexes $\left[\mathrm{Ru}_{2} \mathrm{Cl}_{3}\left(\mathrm{P}(p \text {-tolyl })_{3}\right)_{2}(\mathrm{R}-\mathrm{DAB})_{2}\right]\left(\mathrm{BF}_{4}\right)$ which have been characterized by spectroscopic methods. In addition, one of the complexes was characterized using X-ray crystallography. Meanwhile, two mononuclear Ru(II) complexes $\left[\mathrm{RuCl}_{2}\left(\mathrm{P}(p \text {-tolyl })_{3}\right)_{2}(\mathrm{R}-\mathrm{DAB})\right]$ were obtained from the reactions of the $\left[\mathrm{RuCl}_{2}\left\{\mathrm{P}(p \text {-tolyl })_{3}\right\}\right]$ precursor with R-DAB ligands in THF. The two trans-mononuclear complexes were characterized by X-ray crystallography and solid-state ${ }^{31} \mathrm{P} N M R$. A temperature-dependent ${ }^{31} \mathrm{P}$ NMR study was carried out to monitor the formation of dinuclear and mononuclear complexes.
\end{abstract}

\section{Introduction}

A number of derivatives of 1,4-diaza-1,3-butadiene, also known as diazabutadiene (R-DAB), and their complexes have been reported in the past decades [1-6]. Coordination between the R-DAB ligand and metal centre generally occurs through the two nitrogen atoms of the imine groups, giving complexes with five-membered chelate rings [1,7]. Such five-membered chelate ring ruthenium complexes have drawn significant attention in view of the remarkable photophysical properties of ruthenium bipyridine (bpy) complexes [8-12]. However, compared with ruthenium bpy complexes, the synthesis of ruthenium R-DAB complexes is much less documented. This can in part be attributed to the formation of dinuclear ruthenium complexes instead of the mononuclear analogues. Although several dinuclear ruthenium R-DAB complexes were reported in the 1980s and 1990s,

Electronic supplementary material The online version of this article (https://doi.org/10.1007/s11243-018-00293-0) contains supplementary material, which is available to authorized users.

Meng Guan Tay

mgtay@unimas.my

1 Faculty of Resource Science and Technology, Universiti Malaysia Sarawak, 94300 Kota Samarahan, Sarawak, Malaysia
[4, 13-16], mononuclear ruthenium R-DAB complexes are more rare. In 1980, Chaudret and Poilblanc [13] reported the formation of dinuclear ruthenium R-DAB complexes with three proposed structures; but they could not identify the exact structures of these complexes. In 2014, Ghosh and co-workers reported mononuclear ruthenium R-DAB complexes obtained from the reaction between the precursor complex dichlorotris[tri( $p$-\{tolyl $\})$ phosphine] ruthenium(II), $\left[\mathrm{RuCl}_{2}\left\{\mathrm{P}(p \text {-tolyl })_{3}\right\}_{3}\right.$ and R-DAB ligands [17]. Surprisingly, although we used similar methodology to that reported by Ghosh et al. in our own subsequent studies, the ruthenium R-DAB complexes obtained were dinuclear analogues rather than the mononuclear molecules. This has drawn our interest to further investigate the formation of dinuclear as well as mononuclear ruthenium R-DAB complexes by using the $\mathrm{R}-\mathrm{DAB}$ ligands as shown in Scheme 1. In addition, a ${ }^{31} \mathrm{P}$ NMR temperature-dependent study has been carried out in order to gain insight into the formation of dinuclear versus mononuclear complexes. The outcome of these experiments is presented herein. 